\title{
PERBANDINGAN KEMAMPUAN REGRESSION TESTING TOOL PADA REGRESSION TEST SELECTION: STARTS DAN EKSTAZI
}

\author{
Asri Maspupah', Akhmad Bakhrun ${ }^{2}$ \\ 1,2Jurusan Teknik Komputer dan Informatika, Politeknik Negeri Bandung \\ Email: ${ }^{1}$ maspupah@polban.ac.id, ${ }^{2}$ abakhrun@polban.ac.id
}

\begin{abstract}
Abstrak
Regression testing sebagai aktivitas esensial pada pengembangan software yang mengalami perubahan requirement. Pada pelaksanaannya, regression testing memerlukan waktu yang tidak sedikit sehingga dibutuhkan strategi yang optimal. Salah satu pendekatan yang dapat digunakan untuk mempercepat waktu pelaksanaan yaitu pendekatan Regression Test Selection (RTS). Saat ini, para praktisi maupun akademisi sudah mulai berfikir untuk mengembangkan tools dalam mengoptimalkan proses pelaksanaan regression testing. Diantaranya, STARTS dan Ekstazi merupakan regression testing tools yang paling poluler di kalangan akademisi dalam menjalankan algoritma pemilihan test case. Artikel ini membahas perbandingan kemampuan fitur STARTS dan Ekstazi dengan menggunakan evaluasi parameter feature. Kedua tool tersebut diuji coba dengan data input berupa System Under Test (SUT) dan test case yang sama. Parameter yang digunakan dalam perbandingan tool adalah platform technology, pemilihan test case, functionality, usability dan performance efficiency, kelebihan serta kekurangan tool. Hasil uji coba menunjukkan perbedaan dan persamaan fitur STARTS dan Ekstazi, sehingga dapat digunakan oleh praktisi untuk memanfaatkan tool pada pelaksaan regression testing yang sesuai dengan kebutuhannya. Selain itu, hasil eksperimen menunjukkan bahwa penggunaan Ekstazi lebih tepat dalam memilah test case yang penting dan lebih efisien, jika dibandingkan dengan STARTS dan pengujian regressi dengan retest all.
\end{abstract}

Kata Kunci: perbandingan kemampuan tool, regression testing, regression test selection, STARTS, Ekstazi

\begin{abstract}
Regression testing as an essential activity in software development that has changed requirements. In practice, regression testing requires a lot of time so that an optimal strategy is needed. One approach that can be used to speed up execution time is the Regression Test Selection (RTS) approach. Currently, practitioners and academics have started to think about developing tools to optimize the process of implementing regression testing. Among them, STARTS and Ekstazi are the most popular regression testing tools among academics in running test case selection algorithms. This article discusses the comparison of the capabilities of the STARTS and Ekstazi features by using feature parameter evaluation. Both tools were tested with the same input data in the form of System Under Test (SUT) and test cases. The parameters used in the tool comparisons are platform technology, test case selection, functionality, usability and performance efficiency, the advantages, and disadvantages of the tool. he results of the trial show the differences and similarities between the features of STARTS and Ekstazi, so that it can be used by practitioners to take advantage of tools in the implementation of regression testing that suit their needs. In addition, experimental results show that the use of Ekstazi is more precise in sorting out important test cases and is more efficient, when compared to STARTS and regression testing with retest all.
\end{abstract}

Keywords: study comparative tools, regression testing, regression test, STARTS, Ekstazi 


\section{PENDAHULUAN}

Regression testing merupakan salah satu aktivitas pengujian software yang esensial digunakan pada metode pengembangan software dengan siklus perubahan secara berskala pada agile development (Faizullah and Almutairi, 2018). Regression testing digunakan untuk menemukan defect atau error pada bagian software yang sudah dipastikan benar sebelumnya sebagai akibat dari software yang telah dimodifikasi (Simanca et al., 2019) (Rosero, Gómez and Rodríguez, 2017) (Ali et al., 2019). Proses pelaksanaan regression testing, yaitu menjalankan kembali test case yang telah dijalankan untuk memeriksa defect baru atau defect yang telah diperbaiki muncul kembali (Rosero, Gómez and Rodríguez, 2017).

Metode yang paling umum digunakan oleh praktisi industri dalam melaksanakan regression testing adalah pemilihan test case berdasarkan experience based dari tester. Namun strategi ini sulit dilakukan untuk memilih test case yang relevan dalam menguji kode program yang mengalami perubahan. Sementara pada strategi lain, pemilihan test case dengan retest all, yaitu penggunaan kembali semua test case untuk menjamin kebenaran software akibat adanya perubahan kode program. Meskipun dengan pendekatan tersebut proses pengujian regresi memakan banyak waktu dan sumber daya (Engström and Runeson, 2010)(Ansari et al., 2016).

Beberapa peneliti mulai tertarik membahas metoda pelaksanaan regression testing tool untuk meminimalkan waktu pengujian. Salah satunya dengan memilih test case yang penting untuk dijalankan pada pelaksanaan pengujian regresi.

Regression Test Selection (RTS) merupakan salah satu metode untuk mempercepat waktu pelaksanaan pengujian dengan memilih test case yang penting untuk dijalankan berdasarkan kriteria tertentu (Gligoric, Eloussi and Marinov, 2015). Saat ini penelitian mengenai RTS sudah banyak yang mengusulkan beberapa algoritma dalam pemilihan test case. Namun, algoritma yang paling popular diusulkan oleh (Legunsen et al., 2016) (Legunsen, Shi and Marinov, 2017) dan (Gligoric, Eloussi and Marinov, 2015), yaitu algoritma static dan lightweight regression test selection.

Dalam penelitiannya, Legunsen membuat STARTS dengan menggunakan algoritma static regression test selection untuk membuktikan algoritmanya dapat mengurangi waktu pelaksanaan pengujian. Penelitian Legusen telah dirujuk sebanyak 29 kali oleh para peneliti untuk membuktikan hipotesanya dalam berbagai kasus.
Sementara, Gligoric membuat Ekstazi dengan menggunakan algoritma lightweight regression test selection. Tujuan penelitian Gligoric hampir sama dengan Legunsen untuk mencari algoritma RTS dalam mencari test case yang efisien dan efektif dalam menemukan defect karena adanya perubahan kode program. Penelitian Gligoric telah dirujuk sebanyak 39 kali oleh para peneliti.

Berdasarkan fenomena di atas, regression testing tools dengan metode RTS mampu mengurangi waktu pelaksanakan pengujian pada pendekatan retest all. Dengan demikian, penelitian ini membahas perbandingan kemampuan tools, yaitu STARTS dan Ekstazi, untuk melaksanakan regression testing yang menggunakan metode RTS. Perbandingan regression testing tools bertujuan untuk melihat persamaan dan perbedaan fitur tool agar dapat digunakan oleh praktisi sesuai dengan kebutuhannya. Manfaat dari penelitian ini, para praktisi mendapatkan pengetahuan tentang kajian kedua tools tersebut berdasarkan kriteria yang telah ditetapkan. Secara umum kriteria tersebut digunakan untuk mengetahui instalasi tools, objektif tools, cara kerja tools, dan kinerja tools.

Dengan demikian, penelitian ini menekankan kepada study comparative regression testing tools dengan membandingkan kemampuan tools berdasarkan kriteria perbandingan. Pada penelitian sebelumnya, telah dilakukan study comparative testing tools. Fungsi study comparative testing tools dapat membantu pengguna untuk memilih software testing tools yang sesuai berdasarkan kebutuhan (Gamido and Gamido, 2019). Salah satu peneliti yaitu Gamido pada tahun 2019 melakukan study comparative automation testing tools. Pada penelitiannya, Gamido membandingkan kemampuan tools yang umum digunakan dalam automation testing sesuai dengan tujuan software testing secara umum, yaitu menemukan defect agar software sesuai dengan requirement.

Sistematika penulisan artikel ilmiah ini disusun sebagai berikut: Sesi 1 membahas latar belakang dan tujuan penelitian. Sesi 2 membahas metode yang digunakan pada penelitian ini. Sesi 3 membahas diskusi hasil penelitian. Terakhir sesi 4 membahas kesimpulan.

\section{METODE}

Metode penelitian sebagian besar mengadopsi dari tahapan metode yang dipaparkan oleh (Gamido and Gamido, 2019) pada artikel ilmiah yang berjudul "Comparative Review of the Features of Automated Software Testing Tools". Penelitian dimulai dengan mengidentifikasi tools yang akan dikaji. Kemudian menentukan kriteria pembanding sesuai dengan 
objektif penelitian. Tahap ketiga melakukan eksperimen dengan membandingkan tools berdasarkan kriteria pembanding. Terakhir melakukan evaluasi dan pemberian kesimpulan terhadap studi komparatif tools.

Perbedaan penelitian terdahulu dengan penelitian ini terletak pada aspek objektif penelitian dan kriteria pembandingnya. Objektif penelitian (Gamido and Gamido, 2019) adalah membandingkan automation testing tools, sedangkan objektif fokus kepada pembahasan tools yang dimanfaatkan untuk mendukung proses regression testing. Disisi lain, kriteria pembanding pada penelitian terdahulu menggunakan kriteria yang umum digunakan pada automation testing, seperti cross browser, record playback, script languange, data driven, dan report generation, sedangkan kriteria pembanding evaluasi tools penelitian ini menekankan kepada kinerja tools terhadap performa regression testing.

Penjelasan metode yang digunakan pada penelitian ini dipaparkan pada sub bab di bawah ini.

\subsection{Regression Testing Tools}

Regression testing tools yang dipilih sebagai kajian penelitian pada teknik regression test selection adalah STARTS dan Ekstazi.

(a) STARTS adalah static regression test selection untuk menguji System Under Test (SUT) yang dikembangkan pada base project java maven. STARTS melakukan analisis statis pada dependency keterkaitan antar class untuk menemukan test case yang terkena dampak perubahan kode program (Legunsen, Shi and Marinov, 2017).

(b) Ekstazi adalah java library yang ringan untuk menguji SUT yang dikembangkan pada base project java maven. Ekstazi melakukan pembobotan penskalaan untuk regression test selection berdasarkan file dependency (Gligoric, Eloussi and Marinov, 2015).

STARTS dan Ekstazi merupakan open source untuk melakukan pengujian regresi yang didapatkan dari penyedia tool. STARTS dapat diunduh pada link:

https://github.comTestingResearchIllinois/starts.

Sementara Ekstazi dapat diunduh pada link: http://www.ekstazi.org.

STARTS dan Ekstazi dibuat oleh para akademisi untuk kebutuhan penelitian dalam bidang kajian regression testing tools. Akademisi yang berkonstribusi dalam pembuatan STARTS adalah Owolabi Legunsen, August Shi, dan Darko Marinov. Sementara akamisi adalah berkonstribusi dalam pembuatan Ekstazi adalah Milos Gligoric, Lamyaa Eloussi, and Darko Marinov.

\subsection{Evaluasi Parameter Feature}

Agar diketahui perbedaan dan persamaan fitur dari STARTS dan Ekstazi maka diperlukan parameter pembanding sebagai indikator perbandingan tool pada saat uji coba tool (Gamido and Gamido, 2019). Parameter ini disebut sebagai parameter feature karena berfungsi sebagai dasar perbandingan untuk melihat kemampuan dan kinerja tool pada saat melakukan regression testing.

Teridentifikasi pada beberapa penelitian bahwa untuk melakukan perbandingan dapat mempertimbangkan beberapa poin utama sebagai parameter pembanding. Parameter pembanding yang teridentifikasi adalah support to platforms and technology, functionality, usability, performance efficiency dan kelebihan serta kekurangan tools (Sandin, Yassin and Mohamad, 2016) (Satheesh and Singh, 2017) (Kannan, M; Lokeshwari, 2017) (Rana and Yousuf, 2019) (Gamido and Gamido, 2019). Dengan demikian, evaluasi parameter feature yang digunakan pada penelitian ini ditunjukkan pada Tabel 1. Evaluasi Parameter FeatureTabel 1.

Tabel 1. Evaluasi Parameter Feature

\begin{tabular}{|c|c|c|}
\hline $\begin{array}{l}\text { Parameter } \\
\text { Evaluation }\end{array}$ & Deskripsi & Referensi \\
\hline \multirow[t]{2}{*}{$\begin{array}{l}\text { Cross } \\
\text { Platform }\end{array}$} & $\begin{array}{l}\text { Sistem operasi } \\
\text { yang mendukung. }\end{array}$ & $\begin{array}{l}\text { (Gamido and } \\
\text { Gamido, 2019) }\end{array}$ \\
\hline & $\begin{array}{l}\text { Aspek } \quad \text { yang } \\
\text { dikaji: } \\
\text { platform }\end{array}$ & $\begin{array}{l}\text { (Satheesh and } \\
\text { Singh, 2017) } \\
\text { (Kannan, M; } \\
\text { Lokeshwari, } \\
\text { 2017) }\end{array}$ \\
\hline \multirow[t]{3}{*}{ Functionality } & $\begin{array}{l}\text { kemampuan tools } \\
\text { untuk melakukan } \\
\text { regression } \\
\text { testing. }\end{array}$ & $\begin{array}{l}\text { (Satheesh and } \\
\text { Singh, 2017) } \\
\text { (Kannan, } \\
\text { Lokeshwari, }\end{array}$ \\
\hline & $\begin{array}{l}\text { Aspek } \quad \text { yang } \\
\text { dikaji: }\end{array}$ & $\begin{array}{l}\text { 2017) } \\
\text { (Sandin, Yassin }\end{array}$ \\
\hline & $\begin{array}{lr}\text { Ability, } & \text { kriteria } \\
\text { pemilihan } & \text { test } \\
\text { case, } & \text { teknik } \\
\text { pemilihan test } & \text { case; run tool, } \\
\text { dan output tools }\end{array}$ & $\begin{array}{l}\text { and Mohamad, } \\
\text { 2016) }\end{array}$ \\
\hline \multirow[t]{2}{*}{ Usability } & $\begin{array}{l}\text { Kemudahan } \\
\text { dalam memahami } \\
\text { dan memperlajari } \\
\text { tools. }\end{array}$ & $\begin{array}{l}\text { (Gamido and } \\
\text { Gamido, 2019) } \\
\text { (Satheesh and } \\
\text { Singh, 2017) }\end{array}$ \\
\hline & $\begin{array}{l}\text { Aspek yang } \\
\text { dikaji: } \\
\text { Pemahaman } \\
\text { dokumentasi, } \\
\text { mudah } \\
\text { digunakan, dan } \\
\text { mudah untuk } \\
\text { diinstalasi. }\end{array}$ & $\begin{array}{l}\text { (Sandin, Yassin } \\
\text { and Mohamad, } \\
\text { 2016) }\end{array}$ \\
\hline
\end{tabular}




\begin{tabular}{|c|c|c|}
\hline $\begin{array}{l}\text { Parameter } \\
\text { Evaluation }\end{array}$ & Deskripsi & Referensi \\
\hline \multirow[t]{2}{*}{$\begin{array}{l}\text { Performance } \\
\text { efficiency }\end{array}$} & $\begin{array}{l}\text { Tingkat kinerja } \\
\text { tools pada } \\
\text { beberapa kondisi. }\end{array}$ & \multirow{2}{*}{$\begin{array}{l}\text { (Gamido and } \\
\text { Gamido, 2019) } \\
\text { (Satheesh and } \\
\text { Singh, 2017) }\end{array}$} \\
\hline & $\begin{array}{ll}\text { Aspek } & \text { yang } \\
\text { dikaji: } & \\
\text { Run } & \text { time } \\
\text { execution } & \\
\end{array}$ & \\
\hline \multirow[t]{2}{*}{ Other } & $\begin{array}{l}\text { Temuan pada saat } \\
\text { dilakukan uji } \\
\text { coba tools. }\end{array}$ & $\begin{array}{l}\text { (Gamido and } \\
\text { Gamido, 2019) } \\
\text { (Rana and }\end{array}$ \\
\hline & $\begin{array}{l}\text { Aspek } \quad \text { yang } \\
\text { dikaji: } \\
\text { Kelebihan } \\
\text { kekurangan }\end{array}$ & Yousuf, 2019) \\
\hline
\end{tabular}

\subsection{Perbandingan Kemampuan Tool}

Perbandingan kemampuan tool digunakan untuk menunjukkan perbedaan dan persamaan STARTS dan Ekstazi. Proses perbandingan tool menggunakan metode exploratory study berdasarkan uji coba eksperimen (Edgar and Cyber, 2017). Setiap tool diuji coba dengan menjalankannya untuk mengetahui defect pada skema pelaksanaan proses regression testing. Skema pengujian pada regression testing melibatkan dua kali pengujian untuk mengetahui defect pada pengujian ulang sebagai dampak dari perubahan requirement (Ali et al., 2019). Dengan demikian, eksperimen perbandingan performa kedua tools melalui pengamatan proses regression testing pada pengujian SUT yang kedua. Pengamatan dilakukan berdasarkan evaluasi parameter feature.

Proses regression testing dilakukan terhadap sebuah kasus uji coba pada SUT yang telah dimodifikasi. Skema uji coba mengadopsi pengujian regresi yang melibatkan dua kali proses pengujian.

Pengujian pertama, pengujian SUT setelah implementasi kode program selesai. Pengujian ini bertujuan untuk mengetahui defect sebagai akibat kesalahan kode program yang tidak sesuai dengan requirement. Setelah pengujian pertama dilakukan, dihasilkan defect kemudian diperbaiki sehingga sesuai dengan requirement. Pengujian pertama memastikan bahwa SUT telah diimplementasikan dengan benar sesuai dengan requirement.

Pengujian kedua, pengujian SUT setelah implementasi perubahan kode program selesai. Pengujian ini bertujuan untuk mengetahui defect pada bagian kode program yang tidak terkena dampak perubahan. Jika terjadi defect, hal ini disebabkan oleh kesalahan perubahan kode program. Pengujian kedua memastikan bahwa perubahan kode program tidak mengakibatkan defect pada kode program yang tidak terkena dampak perubahan.

Uji coba pelaksanaan regression testing pada STARTS dan Ekstazi menggunakan data SUT dan test case yang sama. Karakteristik SUT dan test case ditunjukkan pada Tabel 2.

Tabel 2. Karakteristik Data Input Eksperimen

\begin{tabular}{lll}
\hline $\begin{array}{c}\text { Jenis Data } \\
\text { Masukan }\end{array}$ & \multicolumn{1}{c}{ Deskripsi } & \multicolumn{1}{c}{$\begin{array}{c}\text { Data } \\
\text { Masukan }\end{array}$} \\
\hline $\begin{array}{l}\text { System Under } \\
\text { Test (SUT) }\end{array}$ & $\begin{array}{l}\text { Kode program yang } \\
\text { akan diuji. }\end{array}$ & JodaTime \\
\hline Test case & $\begin{array}{l}\text { Sekumpulan data } \\
\text { skenario test case }\end{array}$ & Script test \\
& $\begin{array}{l}\text { yang dibuat dalame } \\
\text { bentuk program pada }\end{array}$ & \\
& level unit testing. & \\
\hline
\end{tabular}

JodaTime sebagai SUT eksperimen, dimana source code-nya dapat diunduh pada link: https://github.com/JodaOrg/joda-time. Sementara dokumentasinya dapat dilihat pada link: https://www.joda.org/joda-time/.

Selanjutnya dilakukan pengamatan terhadap proses, output dan temuan-temuan berdasarkan parameter feature pada saat uji coba eksperimen STARTS dan Ekstazi. Kemudian dilakukan proses analisa perbandingan untuk mengetahui persamaan dan perbedaan fitur dari STARTS dan Ekstazi.

\section{HASIL DAN PEMBAHASAN}

Hasil uji coba eksperimen berupa perbandingan parameter feature pada kemampuan tool.

\subsection{Cross Platform}

Cross platform adalah parameter feature yang membandingkan sistem operasi yang didukung oleh tool. Perbandingan parameter cross platform dijelaskan di bawah ini.

(a) STARTS dijalankan di LinuxOS dan MacOS.

(b) Ektazi dijalan di Windows dan LinuxOS.

\subsection{Functionality}

Functionality adalah parameter feature yang membandingkan kemampuan tool dalam menjalankan proses regression testing. Perbandingan functionality pada STARTS dan Ekstazi ditunjukkan pada Tabel 3.

Berdasarkan Tabel 3, perbandingan functionality pada STARTS dan Ekstazi menunjukkan adanya persamaan dan perbedaan. Persamaan terletak pada aspek ability dalam melakukan regression testing, kriteria pemilihan test case, bagaimana menjalankan tool dan keluaran dari tool. Sementara perbedaan terletak pada algoritma dalam memilih test case 
yang sesuai ketika terjadi perubahan kode program, yaitu pada aspek teknik pemilihan test case.

Tabel 3. Perbandingan Parameter Functionality

\begin{tabular}{|c|c|c|}
\hline $\begin{array}{l}\text { Parameter } \\
\text { feature }\end{array}$ & STARTS & Ekstazi \\
\hline ability & \multicolumn{2}{|c|}{$\begin{array}{l}\text { Memilih test case yang penting untuk } \\
\text { dijalankan ulang pada pengujian regresi. } \\
\text { Kemudian menjalankan test case terpilih } \\
\text { untuk melihat defect yang terkena dampak } \\
\text { perubahan. }\end{array}$} \\
\hline $\begin{array}{l}\text { kriteria } \\
\text { pemilihan } \\
\text { test case }\end{array}$ & \multicolumn{2}{|c|}{$\begin{array}{l}\text { Kriteria yang digunakan berdasarkan } \\
\text { perubahan kode program sebagai akibat } \\
\text { modifikasi fitur }\end{array}$} \\
\hline $\begin{array}{c}\text { teknik } \\
\text { pemilihan } \\
\text { test case }\end{array}$ & $\begin{array}{l}\text { Pembuatan } \\
\text { dependency graph } \\
\text { untuk mencari } \\
\text { keterkaitan antar } \\
\text { class. Selanjutnya } \\
\text { melakukan } \\
\text { perhitungan } \\
\text { checksum pada } \\
\text { setiap test case } \\
\text { untuk memilih test } \\
\text { case penting } \\
\text { berdasarkan } \\
\text { perubahan kode } \\
\text { program } \\
\text { (Legunsen } \text { et al., } \\
\text { 2016). }\end{array}$ & $\begin{array}{l}\text { Pembuatan } \\
\text { dependency file } \\
\text { berdasarkan invoke } \\
\text { method. } \\
\text { Selanjutkan } \\
\text { perhitungan fungsi } \\
\text { checksum pada } \\
\text { setiap script test } \\
\text { untuk memilih test } \\
\text { case penting } \\
\text { berdasarkan } \\
\text { perubahan kode } \\
\text { program (Gligoric, } \\
\text { Eloussi and } \\
\text { Marinov, 2015). }\end{array}$ \\
\hline run tool & \multicolumn{2}{|c|}{$\begin{array}{l}\text { Pengaturan konfigurasi SUT pada } \\
\text { pom.xml dengan menambahkan maven } \\
\text { plugin. SUT yang akan diujikan haruslah } \\
\text { project java dengan base maven plugin. } \\
\text { Kemudian menjalankan tool melalui } \\
\text { instruksi command line pada path working } \\
\text { folder SUT. }\end{array}$} \\
\hline output tools & \multicolumn{2}{|c|}{$\begin{array}{l}\text { Menjalankan berdasarkan test case terpilih } \\
\text { kemudian memberikan informasi berupa } \\
\text { log testing. Log testing berisi jumlah test } \\
\text { case yang di-running, jumlah failure, } \\
\text { waktu eksekusi dan status build. }\end{array}$} \\
\hline
\end{tabular}

STARTS dan Ekstazi memandang pemilihan test case berdasarkan perubahan kode program pada saat modifikasi fitur dengan melihat dependency file atau keterkaitan antar class pada SUT. Selanjutnya mencari test case penting yang relevan berdasarkan perubahan kode program dengan menggunakan checksum. Namun algoritma yang digunakan sebagai kriteria dasar untuk membuat dependency memiliki cara yang berbeda. STARTS membuat dependency graph, sedangkan Ekstazi membuat dependency file berdasarkan invoke method.

Pada saat pemilihan test case relevan dengan perubahan kode program, algoritma yang digunakan pada STARTS dan ekstazi menggunakan fungsi checksum. Fungsi checksum menghasilkan sebuah string yang mewakili isi kode program dan tipe tertentu. Nilai checksum akan berubah ketika terjadi perubahan kode program (Gligoric, Eloussi and Marinov, 2015).

Nilai checksum menentukan apakah kode program yang sedang diuji mengalami perubahan. Perubahan diketahui jika terdapat perbedaan nilai checksum dengan nilai sebelumnya. Hasil fungsi checksum disimpan di dalam suatu file perhitungan. STARTS dan Ekstazi akan menggunakan nilai checksum untuk menentukan apakah test case perlu digunakan kembali pada pengujian regresi.

STARTS memanfaatkan nilai checksum untuk melakukan analisis statis dengan menggunakan dependency graph. Analisis statis tersebut bertujuan untuk mengetahui keterkaitan antar class pada source code. Selanjutnya dilakukan analisa pemilihan test case dengan menganalisis apakah test case dapat meraih suatu SUT yang mengalami perubahan kode program pada dependency graph. Apabila test case tersebut memiliki keterhubungan dengan SUT maka test case tersebut terpilih menjadi test case yang akan diujikan kembali. Kemudian STARTS menyimpan hasil perhitungan checksum dalam satu file yang berisi sekumpulan test (set of test) yang bergantung kepada suatu file tertentu (Legunsen, Shi and Marinov, 2017).

Sementara Ekstazi memanfaatkan nilai checksum untuk melakukan analisis sederhana. Perhitungan nilai checksum dilakukan pada setiap test case. Pada saat Ekstazi digunakan pada saat pertama kali, tidak ada informasi dependence untuk semua class, sehingga semua class dipilih untuk retest all. Pada akhir proses setiap test case memiliki nilai checksum. Pada pengujian kedua, ekstazi memeriksa apakah nilai checksum pada file dependence masih sama. Jika sama maka test case tersebut tidak dipilih (Gligoric, Eloussi and Marinov, 2015).

\subsection{Usability}

Usability adalah parameter feature yang membandingkan kemudahan dalam proses pembelajaran tools. Tingkat kemudahan pada ketiga parameter usability dikategorikan ke dalam mudah, sedang dan sulit. Penjelasan masing-masing kategori dijelaskan pada Tabel 4.

Setelah didapatkan hasil eksperimen perpandingan kemampuan tools dengan melihat parameter usability, selanjutnya adalah memetakan kemampuan usability tools ke dalam kategori tingkat kemudahan. Kategori tingkat kemudahan ini ditunjukkan pada Tabel 4. Berdasarkan analisa dari hasil eksperimen, maka didapatkan hasil perbandingan kemampuan STARTS dan Ekstazi yang ditinjau dari aspek parameter usability pada ditunjukkan pada Tabel 5. 
Tabel 4. Penjelasan Tingkat Kemudahan

\begin{tabular}{|c|c|}
\hline Kategori & Deskripsi \\
\hline \multirow[t]{5}{*}{ Mudah } & Aspek: Pemahaman Dokumentasi \\
\hline & $\begin{array}{l}\text { Tersedianya dokumentasi di jejaring } \\
\text { internet baik yang disediakan oleh } \\
\text { website penyedia tools atau para peneliti } \\
\text { yang menjelaskan kinerja tools (Sandin, } \\
\text { Yassin and Mohamad, 2016). }\end{array}$ \\
\hline & Aspek: Mudah digunakan \\
\hline & $\begin{array}{l}\text { Sebuah prosedur memiliki langkah- } \\
\text { langkah penggunaan yang mudah untuk } \\
\text { diingat (Churm, 2017). }\end{array}$ \\
\hline & $\begin{array}{l}\text { Aspek Kemudahan Instalasi } \\
\text { Pada saat instalasi memiliki pengaturan } \\
\text { konfigurasi yang sederhana yaitu tidak } \\
\text { banyak yang harus diatur (Satheesh and } \\
\text { Singh, 2017). }\end{array}$ \\
\hline \multirow[t]{5}{*}{ Sedang } & Aspek: Pemahaman Dokumentasi \\
\hline & $\begin{array}{l}\text { Tersedianya dokumentasi penjelasan } \\
\text { tools, tetapi membutuhkan upaya agar } \\
\text { kinerja tools dipahami (Sandin, Yassin } \\
\text { and Mohamad, 2016). }\end{array}$ \\
\hline & Aspek: Mudah digunakan \\
\hline & $\begin{array}{l}\text { Sebuah prosedur memiliki langkah- } \\
\text { langkah penggunaan yang agak susah } \\
\text { untuk diingat (Churm, 2017) }\end{array}$ \\
\hline & $\begin{array}{l}\text { Aspek Kemudahan Instalasi } \\
\text { Jika ditinjau dari pernyataan statheesh } \\
\text { maka yang termasuk kategori sedang } \\
\text { yang tools yang memiliki pengaturan } \\
\text { yang tidak terlalu sederhana, tetapi tidak } \\
\text { terlalu komplek. }\end{array}$ \\
\hline \multirow[t]{5}{*}{ Sulit } & Aspek: Pemahaman Dokumentasi \\
\hline & $\begin{array}{l}\text { Tersedianya dokumentasi penjelasan } \\
\text { tools, tetapi membutuhkan upaya lebih } \\
\text { agar kinerja tools dipahami atau bahkan } \\
\text { dokumentasi tidak tersedia (Sandin, } \\
\text { Yassin and Mohamad, 2016) }\end{array}$ \\
\hline & Aspek: Mudah digunakan \\
\hline & $\begin{array}{l}\text { Sebuah prosedur memiliki langkah- } \\
\text { langkah penggunaan yang susah untuk } \\
\text { diingat (Churm, 2017) }\end{array}$ \\
\hline & $\begin{array}{l}\text { Aspek Kemudahan Instalasi } \\
\text { Pada saat instalasi memiliki pengaturan } \\
\text { konfigurasi framework yang rumit yaitu } \\
\text { banyak yang harus diatur (Satheesh and } \\
\text { Singh, 2017) }\end{array}$ \\
\hline
\end{tabular}

Tabel 5. Perbandingan Parameter Usability

\begin{tabular}{lcc}
\hline \multicolumn{1}{c}{ Parameter feature } & STARTS & Ekstazi \\
\hline Pemahaman dokumentasi. & sedang & mudah \\
\hline Mudah digunakan & mudah & mudah \\
\hline Kemudahan instalasi & mudah & mudah \\
\hline
\end{tabular}

Tabel 5 menggambarkan perbandingan STARTS dan Ekstazi pada parameter usability berdasarkan aspek kajian tingkat kemudahan dalam pemahaman dokumentasi, kemudahan penggunaan tools dan kemudahan instalasi tools. Aspek dokumentasi membahas mengenai tingkat kemudahan dalam memahami informasi terkait instalasi dan penggunaan tool yang disediakan tool.

Ditinjau dari aspek tingkat kemudahan pemahaman dokumentasi, STARTS termasuk ke dalam kategori sedang karena dokumentasi yang tersedia tidak lengkap sehingga untuk mendapatkan informasi instalasi dan penggunaan tool harus mencari sumber lain. Sementara Ekstazi sudah banyak tersedia dokumentasi yang menjelaskan instalasi dan penggunaan tools dengan bahasa yang mudah dimengerti.

Sementara ditinjau dari aspek kemudahan dalam penggunaan tool, STARS dan Ekstazi termasuk ke dalam kategori mudah karena menggunakan instruksi yang sederhana melalui command line. STARS dijalankan dengan instruksi mvn starts:starts, sedangkan ekstazi dijalankan dengan instruksi ekstazi:ekstazi pada path working folder SUT.

Disisi lain, jika ditinjau dari aspek kemudahan instalasi tools, STARS dan Ekstazi termasuk ke dalam kategori mudah karena cukup melakukan pengaturan konfigurasi penambahan library tools pada SUT melalui pom.xml secara sederhana. Konfigurasi pada tahap instalasi tool bertujuan untuk menambahkan plugin STARTS atau Ekstazi di dalam working folder SUT. Pengaturan konfigurasi STARTS ditunjukkan pada Tabel 6, sedangkan konfigurasi Ekstazi ditunjukkan pada Tabel 7.

Tabel 6. Konfigurasi Penambahan Plugin STARTS

\begin{tabular}{|c|c|}
\hline File & pom.xml \\
\hline \multicolumn{2}{|c|}{ Sintaksis } \\
\hline \multicolumn{2}{|c|}{ <build $>$} \\
\hline \multicolumn{2}{|c|}{$<$ plugins $>$} \\
\hline \multicolumn{2}{|c|}{$<$ plugin $>$} \\
\hline \multicolumn{2}{|c|}{ <groupId>edu.illinois</groupId $>$} \\
\hline \multicolumn{2}{|c|}{ <artifactId>starts-maven- } \\
\hline & lugin</artifactId $>$ \\
\hline & sion $>1.3</$ version $>$ \\
\hline$</ p$ & in> \\
\hline$</$ bui & \\
\hline
\end{tabular}

Tabel 7. Konfigurasi Penambahan Plugin Ekstazi

\begin{tabular}{|c|c|}
\hline File & pom.xml \\
\hline \multicolumn{2}{|c|}{ Sintaksis } \\
\hline \multicolumn{2}{|c|}{ <build $>$} \\
\hline \multicolumn{2}{|c|}{$<$ plugins > } \\
\hline \multicolumn{2}{|c|}{$<$ plugin $>$} \\
\hline \multicolumn{2}{|c|}{ <artifactId>starts-maven- } \\
\hline \multicolumn{2}{|c|}{$\begin{array}{r}\text { plugin }<\text { /artifactId }> \\
<\text { version }>1.3</ \text { version }>\end{array}$} \\
\hline \multicolumn{2}{|c|}{$</$ plugin $>$} \\
\hline \multicolumn{2}{|c|}{$</$ plugins $>$} \\
\hline$</$ but & \\
\hline
\end{tabular}




\subsection{Performance Efficiency}

Performance efficiency adalah parameter feature yang membandingkan tingkat kinerja dalam melakukan eksekusi regression testing. Parameter feature performance efficiency yang digunakan pada penelitian ini berdasarkan kecepatan waktu eksekusi. Uji coba dilakukan dengan mencatat waktu pada saat menjalankan STARTS, Ekstazi dan pengujian dengan pendekatan retest all. Perbandingan kecepatan pengujian regresi ditunjukkan pada Tabel 8.

Tabel 8. Perbandingan Performance Efficiency

\begin{tabular}{ll}
\hline Parameter Feature & Run Time Execution \\
\hline STARTS & 50 detik \\
\hline Ekstazi & 15.238 detik \\
\hline Retest All & 58.972 detik \\
\hline
\end{tabular}

Tabel 8 menunjukkan bahwa Ekstazi memiliki performa yang lebih baik dibandingkan dengan STARTS karena hasil perhitungan pemilihan test case dari metode yang digunakan lebih akurat. Disisi lain, jika dibandingkan dengan waktu yang dibutuhkan ketika pengujian regresi pada retest all, performa STARTS tidak terlalu signifikan, yaitu pengurangan sebesar 15\% sebanyak 8.972 detik dari total waktu retest all (58 detik). Sementara, Ekstazi mampu mengurangi waktu pelaksanaan sebesar 74\% sebanyak 43.734 detik dari total waktu retest all (58 detik). Dengan kata lain, pelaksanakan regression testing oleh Ekstazi lebih cepat 30\% dibandingkan dengan STARTS. Hal ini menunjukkan bahwa proses pemilihan test case pada STARTS tidak jauh lebih baik karena adanya kemungkinan test case tetap dijalankan meskipun tidak terkena dampak perubahan kode program.

\subsection{Other}

Parameter feature yang membandingkan temuan-temuan pada saat uji coba eksperimen yang ditinjau dari tiga aspek yaitu kekurangan dan kelebihan tool. Penjelasan perbandingan parameter feature other dipaparkan di bawah ini.

a. Kelebihan tool

1) STARTS memiliki kemudahan pada saat pengaturan konfigurasi dengan SUT dan kemudahan pada saat digunakan. Hal ini selaras dengan hasil analisa komparatif yang ditinjau dari parameter usability.

2) Ekstazi memiliki kelebihan dalam pengecekan yang lebih akurat. Hal ini karena semua method dievaluasi dan mengindentifikasi kemungkinan yang terjadi selama pengujian dijalankan. Misalnya, defect yang ditemukan. Pengecekan dengan tingkat akurasi ini akan memudahkan untuk mengetahui sisi mana yang terdapat defect atau di metode mana, baris kode, dan berapa banyak defect yang ditemukan (Legunsen et al., 2016) (Legunsen, Shi and Marinov, 2017).

b. Kekurangan tool

1) STARTS memiliki kekurangan sbb:

Algoritma pemilihan test case yang digunakan berdasarkan perubahan kode program, terdapat perhitungan presisi yang tidak akurat. Hal ini menyebabkan gagalnya proses pemilihan test case yang penting sehingga besar kemungkinan tidak terjadi pengurangan test case (Legunsen, Shi and Marinov, 2017).

2) Sementara Ekstazi memiliki kekurangan sbb:

Pada saat pelaksanaan regression testing, Ekstazi sangat berpengaruh terhadap versi JUnit yang diintegrasikan. Pada saat diintegrasikan dengan JUnit versi 3, Ekstazi hanya mendukung pembuatan dependency file pada level method (bukan class). Sementara jika diintegrasikan dengan JUnit versi 4, Ekstazi hanya mendukung pembuatan dependency file pada level class (bukan method) (Gligoric, Eloussi and Marinov, 2015). Oleh karena adanya perbedaan versi dependency file yang tergantung dari versi Junit yang digunakan, menurut penulis akan berdampak pada kebutuhan regression testing, yaitu jika ingin mengecek berdasarkan level method atau level class harus berganti versi JUnit.

\section{PENUTUP}

\section{Kesimpulan}

Perbandingan kemampuan regression test selection pada kedua tools menunjukkan perbedaan performa yang ditinjau dari parameter feature yang telah ditentukan. Perbedaan tersebut terletak kepada environment tools, teknik pemilihan test case, tingkat keakuratan, kemudahan mendapatkan dokumentasi penggunaan tools, time execution dan instalasi tools. Perbandingan tersebut dapat pula menunjukkan persamaan, yaitu terletak pada ability tools, output tools, cara melakukan running tools, kriteria pemilihan test case, dan kemudahan dalam instalasi dan penggunaan tools. 
Selain itu, perbandingan kemampuan tools pada proses pemilahan test case menunjukkan tingkat keakuratan tools dalam menjalankan regression testing. Analisa hasil eksperimen menunjukkan bahwa metoda regression testing dengan RTS mampu mengurangi waktu pelaksanaan regression testing pada metode retest all. Ekstazi mampu mengurangi waktu pelaksanaan pengujian sebanyak $74 \%$ dari retest all. Disisi lain, pemilihan test case bagian kode program yang harus diuji kembali sebagai dampak dari perubahan kode pada Ekstazi lebih cepat $30 \%$ dan lebih akurat dibandingkan dengan STARTS. Dengan demikian, Ekstazi merupakan pilihan yang tepat untuk RTS dengan tingkat keakuratan dan kecepatan eksekusi yang baik.

Pada akhir penelitian disimpulkan bahwa dari parameter feature, yaitu cross platform, functionality, usability, performance efficiency, kelebihan dan kekurangan tools, dapat digunakan untuk melihat perbedaan \& persamaan fitur tools sehingga informasinya bermanfaat kepada praktisi dalam rangka memanfaatkan tool untuk pelaksanaan regression testing yang disesuaikan dengan kebutuhannya.

\section{Saran}

Berdasarkan temuan hasil penelitian ini, pengembangan penelitian berikutnya dapat dengan menambahkan parameter feature untuk mengevaluasi regression testing tool. Selain itu, penambahan tools yang dibandingkan, selain STARTS dan Ekstazi, agar dapat menambahkan variasi tools yang dapat dimanfaatkan pada regression testing.

\section{DAFTAR PUSTAKA}

Ali, N. bin et al. (2019) On the search for industryrelevant regression testing research, Empirical Software Engineering. doi: 10.1007/s10664-018-9670-1.

Ansari, A. et al. (2016) 'Optimized Regression Test Using Test Case Prioritization', Procedia Computer Science, 79, pp. 152-160. doi: 10.1016/j.procs.2016.03.020.

Churm, T. (2017) An Introduction To Website Usability Testing, Usability Geek, [online]. Available at: https://usabilitygeek.com/anintroduction-to-website-usability-testing/ (Accessed: 28 November 2020).
Edgar, T. W. and Cyber, S. (2017) 'About the Authors', Research Methods for Cyber Security, p. xv. doi: 10.1016/b978-0-12805349-2.00020-0.

Engström, E. and Runeson, P. (2010) 'A qualitative survey of regression testing practices', Lecture Notes in Computer Science (including subseries Lecture Notes in Artificial Intelligence and Lecture Notes in Bioinformatics), 6156 LNCS(June), pp. 3-16. doi: 10.1007/978-3-642-13792-1_3.

Faizullah, S. and Almutairi, S. (2018) 'Considerations for Regression Testing Process in Agile Development Environments', International Journal of Advanced Research in Computer Science and Software Engineering, 8(1), p. 153. doi: 10.23956/ijarcsse.v8i1.565.

Gamido, H. V. and Gamido, M. V. (2019) 'Comparative review of the features of automated software testing tools', International Journal of Electrical and Computer Engineering, 9(5), pp. 4473-4478. doi: 10.11591/ijece.v9i5.pp4473-4478.

Gligoric, M., Eloussi, L. and Marinov, D. (2015) 'Ekstazi: Lightweight Test Selection', Proceedings - International Conference on Software Engineering, 2, pp. 713-716. doi: 10.1109/ICSE.2015.230.

Kannan, M; Lokeshwari, K. (2017) 'Available Online at www.ijarcs.info COMPARISON OF SOFTWARE TESTING TOOLS WITH RESPECT TO TOOLS', International Journal of Advanced Research in Computer Science, 8(0976).

Legunsen, O. et al. (2016) 'An extensive study of static regression test selection in modern software evolution', Proceedings of the ACM SIGSOFT Symposium on the Foundations of Software Engineering, 13-18-November2016, pp. 583-594. doi: $10.1145 / 2950290.2950361$.

Legunsen, O., Shi, A. and Marinov, D. (2017) 'STARTS: STAtic regression test selection', 32nd IEEE/ACM International Conference on Automated Software Engineering (ASE), 3(6), pp. 949-954. 
Rana, K. and Yousuf, M. M. (2019) 'Comparative Analysis of the Automated Penetration Testing Tools', Journal of Emerging Technologies and Innovative Research, 5(10), pp. 585-591. Available at: http://trap.ncirl.ie/4165/.

Rosero, R. H., Gómez, O. S. and Rodríguez, G. (2017) 'An approach for regression testing of database applications in incremental development settings', 6th International Conference on Software Process Improvement (CIMPS), pp. 1-4.

Sandin, E. V., Yassin, N. M. and Mohamad, R. (2016) 'Comparative Evaluation of Automated Unit Testing Tool for PHP', International Journal of Software Engineering and Technology, 3(2), pp. 7-11. Available at: http://ijset.fc.utm.my/ijset/index.php/ijset/art icle/viewFile/60/31.

Satheesh, A. and Singh, M. (2017) 'Comparative Study of Open Source Automated Web Testing Tools: Selenium and Sahi', Indian Journal of Science and Technology, 10(13), pp. $1-9$. doi: 10.17485/ijst/2017/v10i13/109048.

Simanca, F. et al. (2019) 'A Solution to Manage the Full Life Cycle of Learning Analytics in a Learning Management System: AnalyTIC', IEEE Revista Iberoamericana de Tecnologias del Aprendizaje, PP(c), p. 1. doi: 10.1109/RITA.2019.2950148. 